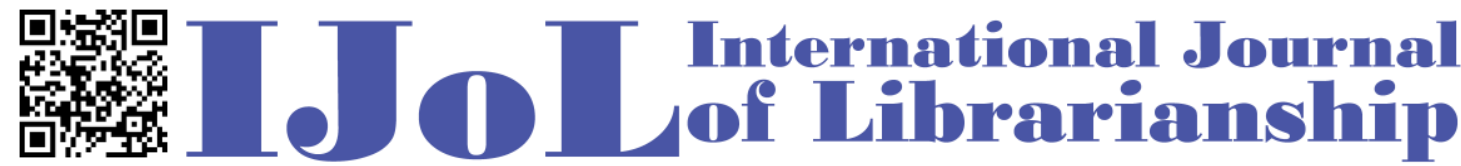

ISSN: 2474-3542 Journal homepage: http://journal.calaijol.org

\section{Is it Necessary: Quality Control in Cataloging?}

\author{
Muriel D. Nero and Jia He
}

\begin{abstract}
:
Catalogers and technical services departments have always struggled with how much is too much when creating and enhancing bibliographic records as well as with what physical processing is needed to make these materials shelf-ready for timely circulation. Along with these decisions, catalogers also must address what quality control measures, if any, should be in place to guarantee resources are discoverable in the OPAC and discovery service. The authors of this paper describe their process and workflow for the quality control of tangible and electronic resources; they also discuss why quality control is performed. The importance of training cataloging staff on current cataloging rules and practices as a preventive measure to reduce mistakes is an essential part of the process. The ultimate goal of quality control is to eliminate errors and ensure the library's resources are accessible.
\end{abstract}

To cite this article:

Nero, M.D., \& He, J. (2018). Is it necessary: Quality control in cataloging? International Journal of Librarianship, 3(2), 85-95.

To submit your article to this journal:

Go to http://ojs.calaijol.org/index.php/ijol/about/submissions 


\title{
Is it Necessary: Quality Control in Cataloging?
}

\author{
Muriel D. Nero and Jia He \\ The Marx Library of the University of South Alabama, Mobile, Alabama, USA
}

\begin{abstract}
Catalogers and technical services departments have always struggled with how much is too much when creating and enhancing bibliographic records as well as with what physical processing is needed to make these materials shelf-ready for timely circulation. Along with these decisions, catalogers also must address what quality control measures, if any, should be in place to guarantee resources are discoverable in the OPAC and discovery service. The authors of this paper describe their process and workflow for the quality control of tangible and electronic resources; they also discuss why quality control is performed. The importance of training cataloging staff on current cataloging rules and practices as a preventive measure to reduce mistakes is an essential part of the process. The ultimate goal of quality control is to eliminate errors and ensure the library's resources are accessible.
\end{abstract}

Keywords: cataloging, quality control, technical services, cataloging staff training

\section{INTRODUCTION}

Quality control is most often found in the business world; indeed, some companies have an entire department committed to the quality control of their products. The Marx Library Cataloging Department of the University of South Alabama uses a similar process of quality control to examine cataloged materials for errors before they are transferred to the Circulation Department for shelving, transferred to other locations, or used to fulfill hold requests for specific titles. At this academic library, the students and faculty are the customers, and the Cataloging Department's purpose is to comply with the component of the library's mission statement that states that one of the goals of the library is to "provide access to research materials at a level appropriate for successful academic performance” (University of South Alabama, n.d.). Performing quality control inspections on cataloged materials provides assurance that students and faculty will have access to the materials they need to complete course assignments and research endeavors.

This paper will begin with a description of the workflow and processes involved in quality control and explain why this is a valuable part of this department's operations. The bibliographic review process for books, DVDs, and e-books and the physical inspection of the tangible resources for the shelves are the main components of the quality control checklist. This includes examining the bibliographic, holdings, and item records in the Voyager Cataloging module as well as checking OCLC to ensure the Marx Library symbol (ACM) has been added to the correct record. Some of the steps for examining the physical processing include checking barcodes, spine labels, 
and the LC Classification (Library of Congress) call number written on DVDs or inside books. Another aspect requires inspecting the physical processing of books done by GOBI Library Solutions from EBSCO. Although time consuming, quality control is important to ensure all cataloged items meet the current cataloging standards and follow local practices for the cohesion of the collection. This practice also ensures the discoverability of resources via the university libraries’ online catalog SOUTHcat, and the EBSCO Discovery Service.

\section{LITERATURE REVIEW}

With the phrase "quality control," most people think of businesses or large companies massproducing products and the inspection of these manufactured goods before they go to consumers. Therefore, the research process for this paper began by specifically searching for the literature on quality control as it pertains to libraries. The search yielded articles spanning three decades, with the earliest publication in 1983 and the latest in 2015, and addressing some aspects of quality control on the following topics: cataloging or technical services, cataloging standards, library catalogs, cataloging evaluation, outsourcing , database quality, metadata quality, bibliographic quality, authority control, continuing education for staff training, and tools to measure quality.

In most of the articles reviewed, the authors discussed how to define quality control, the purpose of quality control, and the role of catalogers in providing quality control. Quality is not easily defined, it has two aspects: extent and accuracy. "Extent" refers to how much information is provided in the bibliographic record, while "accuracy" refers to the correctness of what is supplied by the cataloger (Graham, 1990). Schultz-Jones, Snow, Miksa, \& Hasenyager (2012) expand extent and accuracy to include the details of the bibliographic record, compliance with cataloging standards, workflow of the processes, and user success in finding records.

For the Marx Library Cataloging Department, the quality control process is a fusion of these two definitions with the examination of the MARC fields of bibliographic records as well as the physical processing of physical items for circulation. By doing this, a standard is created that helps build and establish a cohesive and uniform database of resources. Sheeran (1996) shares this same opinion about maintaining a cohesive collection by saying "If libraries are going to continue to provide accurate, efficient access to the materials that they collect, then the database must be maintained in a cohesive, correct manner." Catalogers are essential players in the operation and organization of libraries. Although what they do is behind the scenes, the cataloger's data driven work of inputting crucial elements in the correct MARC fields allows materials to be discoverable in the OPACs. As Harmon (1996) states, "If a cataloger does not put the data in the record, the machine is not going to pull it out."

Paiste (2003) goes beyond the typical reasons for quality control and examines many other factors for total quality management. There is more to quality control than detecting and eliminating errors. It is a continuous process that involves assessing, evaluating, planning, and improving your current activities. Libraries and librarians are service oriented and want to meet the needs of the patrons; therefore, assessing patron needs and expectations, and then implementing the necessary changes will increase patron satisfaction. Paiste (2003) also emphasizes the need for continuous improvement and strategic planning. This allows for

examination of production and service to improve the efficiency of quality control activities. One 
tool to achieve continuous improvement is prevention. The emphasis should be on having knowledge of the cataloging rules and standards to prevent making mistakes and to self-check before the inspection process. "In a total quality environment, the goal is to perform tasks correctly the first time. Rather than review arbitrary quantities of cataloged materials, prevention should be emphasized” (Paiste, 2003). McGurr (2011) reiterates this sentiment on prevention by expressing the need for cataloging departments to be watchful of the workflow practices and not wait for a crisis to happen before changes are made.

At the center of the library is the bibliographic database. Catalogers are responsible for the bibliographic database and their work must be of high quality to provide access to the library's resources (Sheeran, 1996). As noted by Alberto Petrucciani (2015), libraries are the only social institution responsible for the "control, organization, communication, and preservation of information about the published output of human knowledge and expression.”

\section{BACKGROUND}

The University of South Alabama has an enrollment of more than 15,000 students and offers bachelors, masters and doctoral degrees for over 100 academic programs. Besides the Marx Library, the University has three other libraries on campus: the Biomedical Library, the Mitchell College of Business Learning Resource Center, and the Doy Leale McCall Rare Book and Manuscript Library, which is housed in the Marx Library. For this paper, the Marx Library's Cataloging Department will be the focus of the bibliographic and physical quality control process for the Marx Library, the Mitchell College of Business Learning Resource Center, and the Doy Leale McCall Rare Book and Manuscript Library.

The Marx Library has a book budget of $\$ 200,000$, which also includes the purchase of DVDs and single title e-books. This flat budget has been in effect for several years prior to the 2013/2014 fiscal year, which for the University of South Alabama begins on October 1 and ends on September 30. The Marx Library subject librarians begin ordering at the beginning of the fiscal year, and are expected to spend half of the allotted funds by the end of January with the rest being spent by July 1 . The majority of materials requested by faculty and purchased by the Marx Library subject librarians support the university's undergraduate programs. Although some purchases support graduate and doctoral programs, these higher level programs tend to request fewer monographs and are in favor of more costly purchases such as journals and databases.

\section{THE MARX LIBRARY CATALOGING PERSONNEL}

Currently, the Cataloging department of the Marx Library is comprised of two librarians: the Head of Cataloging, and the Cataloging Electronic Resources Librarian. The full-time staff includes an LTA II (Library Technical Assistant) and an LTA I. For most of 2014, there was one librarian and three full-time staff because the Head of Cataloging retired in January of 2014. In 2015, the personnel changed again to two librarians and three fulltime staff. After a staff retirement in the beginning of 2015, the department was back to four, the current personnel. The department also has two student assistants who are scheduled to work 20 hours a week. 
Because this is a small unit, each person has specific and shared cataloging responsibilities. The Head of Cataloging, and the Cataloging Electronic Resources Librarian perform most of the original cataloging as well as copy cataloging for monographs, serials, government documents, and archival resources. The Cataloging Electronic Resources Librarian is primarily responsible for cataloging electronic resources such as e-books and streaming videos. The cataloging of DVDs, the only remaining media collection in the Marx Library, is also under the purview of the Cataloging Electronic Resources Librarian. The Head of Cataloging performs original and complex copy cataloging for all materials regardless of format. The LTA II and LTA I both perform copy cataloging of all print materials but are not responsible for copy cataloging electronic resources or DVDs.

The LTA II is the leader of the quality control inspection process, and the librarians serve as backup inspectors. The LTA II also supervises the student assistants who are responsible for the physical processing of materials. The LTA I takes the lead for cataloging government documents and filters materials that need original cataloging to the librarians. The LTA I also monitors and orders the necessary supplies for physical processing, such as the covers to laminate paperbacks. The LTA II has been in the Cataloging Department since 1980 and has witnessed the evolution of what is considered quality control for the department. Initially, quality control only focused on making sure the LC call number on the spine label matched what was written in the books. Several factors made it necessary to include other steps in the quality control process: the migration to a new ILS (Integrated Library System), the creation of more location holdings, and the training of new cataloging staff.

\section{CATALOGING AND PHYSICAL PROCESSING}

During the cataloging process, catalogers follow these basic steps for copy cataloging: 1) searching by ISBN (International Standard Book Number), author, title, or other command line search in OCLC Connexion Client; 2) selecting and examining the record and making necessary changes such as updating records that do not meet the current cataloging rules and practices, RDA (Resource Description and Access); 3) updating the OCLC holdings to add the Marx Library OCLC symbol to record; 4) exporting the OCLC record to Voyager Cataloging module to overlay the order record; 5) performing authority control of name and subject headings; and 6) saving the record to the database. For original cataloging, the bibliographic record is created in OCLC Connexion Client, and then imported into the Voyager Cataloging module. After the bibliographic record is completed and saved, the holdings record is created to display location and call number, as well as to indicate the number of volumes for multivolume book sets or DVDs. The final steps include adding the barcode to the item record and denoting permanent location and item type. The item record also has fields to add the enumeration (volume number), chronology (month/s), and year of the work. This is also where the items status is noted. The item status remains "in process" until it is removed by the circulation department for shelving.

After the catalogers have completed the cataloging of books, these materials are placed on one of two trucks. Books that have no call number labels or need a corrected call number are placed on one truck, and books that need full physical processing are placed on the other truck. DVDs are placed on a separate truck from the books. This separation of materials allows the student assistants 
to easily discern what needs to be done to the items. If during the cataloging process, a cataloger finds a problem with the physical processing of a book from GOBI, the problem is corrected in the Voyager cataloging module, the book is flagged, and the problem noted so the student will know to make the necessary physical correction. For instance, sometimes the LC call numbers need to be corrected. Most often it is simply a date that needs to be changed because the publication for the paperback edition is different from the hardcover edition.

Government documents and books for the archives are not placed on these trucks because they do not go through the physical processing. For example, books for the Doy Leale McCall Rare Book and Manuscript Library do not receive barcodes or any of the physical processing. Books and media for government documents only receive barcodes and no other physical processing. The SuDoc classification labels are created and applied in the Government Documents Department because these materials are acquired by the Head of Government Documents who assigns the SuDoc classification.

Books ordered from GOBI include minimal physical processing. Before making the transition to GOBI, the library used Baker \& Taylor. With Baker \& Taylor, the library outsourced all physical processing including the laminating of paperbacks. When Baker \& Taylor dropped the academic market, the Marx Library had to switch to GOBI. Since the cost to laminate paperbacks from GOBI was substantially higher; therefore, it was more cost effective to have this done in-house by the student assistants. Currently, the Marx Library pays \$2.67 per book for the following: supply and apply 3M strips, supply and apply date due slips, and generate and apply labels. When materials are not purchased from GOBI, the two student assistants provide all the physical processing which includes the following depending on the item: applying ownership stamps, generating spine labels, affixing date due slips, inserting security strips, laminating paperbacks, and PAM (pamphlet) binding. The catalogers apply the barcodes to books and media during the cataloging process.

For DVDs, the physical processing involves applying barcodes and date due slips to the inside of the DVD case and writing the LC or assigned number on the DVD. However, spine labels are only created for nonfiction titles because they receive LC Classification while feature films do not.

\section{QUALITY CONTROL INSPECTION}

After the students have completed a truck, the LTA II begins the full quality control inspection. The process begins with checking the bibliographic, holdings, and item records in the Voyager Cataloging module, and in OCLC Connexion Client to ensure Marx Library's OCLC holding symbol is on the correct record. The second phase examines the student's physical processing. During this second phase, any errors are noted on a checklist and returned to the cataloger for bibliographic corrections or to the student for physical corrections. An example of a correction that needs to be made by a cataloger is if the LC call number written in the book or on the DVD does not match what is on the holdings record. For physical corrections, the LC call number on the item could be missing volume numbers for multivolume sets if the volume number is coveredup by the placement of the spine label. 
For many years, this detailed quality control process was done but not recorded to track errors. The LTA II was simply reporting the number of trucks being inspected, but there were no actual book counts. In 2014, the new Head of Cataloging realized the truck number does not reflect the amount of work the LTA II was doing. In May 2014, the LTA II began counting the number of books going through the quality control inspection. From May to December 2014, 3384 books went through the quality control process; in 2015, the number was 5508; in 2016, it was 3663; and in 2017, a total of 4766 books went through this process.

\section{E-BOOKS}

Between 2014 and 2017, the Marx Library subscribed to or purchased over 67,309 e-book titles from twelve vendors including ProQuest Ebook Central, EBSCO, Springer, Project Muse, JSTOR, Wiley, Sage, Taylor \& Francis, Science Direct, IGI Global, Oxford Scholarship Online, and ACLS. Among these e-book titles, approximately 90 percent were large vendor packages and 10 percent were individual titles. The quality control process for e-books, whether they are in a large vendor packages or individual titles, is specifically focused on the bibliographic and holdings records; there are no item records for these titles. The Cataloging Electronic Resources Librarian is solely responsible for providing the quality control inspection of e-book records.

For the large e-book vendor packages, MarcEdit is the software used to edit the records. Its basic GUI (Graphical User Interface) is designed for a non-coder and provides many convenient analysis and conversion capabilities that do not require any direct knowledge of programming or scripting (University of Illinois at Urbana-Champaign, n.d.). In other words, MarcEdit is not only easy for people to use, but it can also perform some complicated editing tasks on the e-books' Marc records. With MarcEdit, MARC fields are deleted, added, and validated to accomplish the quality control of the large vendor e-book packages.

In some instances, print and e-books may share the same ISBN number; therefore, the 020 fields for ISBN numbers are deleted to prevent e-book records from overlaying existing print bibliographic records in the catalog. For the purpose of clarity and uniformity, non-Library of Congress subject headings (6xx Fields) are deleted. In addition, all classification fields are deleted such as the 050 field for LC or 082 for Dewey Decimal Classification. Electronic resources do not need an LC call number because they are not tangible items to be shelved, and we have found that displaying call numbers for e-books only causes confusion for students who, after seeing the number, go look for the item in the stacks.

Further quality control processing of e-book records includes the application of RDA to the bibliographic records, since the Marx Library adopted and applied RDA as their cataloging standard in 2013. Currently, most vendor provided MARC records follow RDA. The RDA Helper in MarcEdit is available to correct any issues.

For the consideration of local control and e-book ownership, the University of South Alabama library proxy is added to the Electronic Location and Access (856 field) of each record to place the access restrictions. In MarcEdit, Marc Validator is used to check and verify the accuracy of fields for all records in the e-book package file. If any errors are detected, the 
Cataloging Electronic Resources Librarian will locate the records and fix the fields until no errors are found in the e-book package file.

After the editing, the e-book package file is ready to be uploaded to Voyager. Before the loading process, some e-book records from the package file are randomly selected as test records to check if they are displayed correctly and are accessible in Voyager. If everything goes well, the e-book package file will be split into two separate files. For example: for a 500 records e-book package file, it will be separated in two files: one contains 100 records, the other contains 400 records. The smaller file with 100 records will be sent to the Computer Center where it will be uploaded for a test run before the complete file of records is uploaded to the library catalog. If no problems are found, the entire e-book package file will be uploaded to the Marx Library e-book collections. This process and workflow is also used for the streaming videos.

\section{TRAINING CATALOGING PERSONNEL}

Staff training is essential to maintain the quality of cataloging work. By understanding staffs' and students' professional levels, cataloging proficiency levels, and working patterns, the Cataloging Department is able to offer different training sessions to empower them to contribute to the quality cataloging workflow. Without staff training, bibliographic errors would stymie the cataloging portion of the workflow. Hider \& Tan (2008) define errors by their cause such as "non-application of a rule, misinterpretation of information on sources, poor subject analysis, non-recognition of a piece of information, miscoding, incorrect typography, and so on.” These are all avoidable errors if professionals "are prepared to update their knowledge and skills regularly to meet new metadata challenges and opportunities in the twenty-first century” (Park, Tosaka, Maszaros \& Lu, 2010). This coincides with Khurshid's (1997) Total Quality Management (TQM) philosophy which states quality cataloging greatly depends on the competency of the catalogers. This expertise is acquired by training and development and should be supported by libraries.

To make sure staff is able to learn the newest cataloging information and practices, they are encouraged to view cataloging webinars and attend workshops when feasible. The Head of Cataloging only requires staff to report the date and title of the webinar and the information to be covered. The Head of Cataloging also uses this to report on staff professional development during annual staff evaluations. The Head of the Cataloging Department and the Cataloging Electronic Resources Librarian also conduct cataloging workshops to help staff understand the newest developments concerning cataloging standards and practices. From 2015 to 2016, two workshops were held that covered topics such as Toolbar and Options on OCLC Connexion Client, RDA rules and standards, Voyager cataloging functions, and cataloging reference tools and resources. Follow-up instructions or demonstrations take place during the monthly department meetings when necessary.

\section{STUDENT ASSISTANT TRAINING}

Most student workers do not have any library work experience before they come to work in the Cataloging Department. Because their job responsibilities are solely physical processing, they do 
not need cataloging experience but they do need to be detail oriented. In addition, most of them were born in 1990s so it is easy to train them to work with technology such as using the software to print the spine labels. Plus, they have a strong motivation to gain work experience which will benefit their academic or career development in the future. With proper training, they can handle the physical processing work very well and help improve the output of cataloged materials.

The LTA II is responsible for training the student assistants. She has worked in the Cataloging Department for more than 30 years and has been an integral part of the physical processing of materials and the training of student assistants. Usually, the training sessions take several days and depend on the student's class schedule as well as the quantity of materials available for physical processing. The training sessions include demonstrations of applying call number labels, date due slips, security tapes on different materials, PAM binding, and laminating paperbacks.

Chen (2008) states “under the influence of today’s new trends in the cataloging area along with technological changes, a transformation of the pattern of employment in the library's technical services is already underway." To keep the quality of the cataloging work under this employment pattern, well designed training programs and workshops will not only benefit the career development of professionals and paraprofessionals, but they will also improve the quality of cataloging work.

\section{WHY QUALITY CONTROL?}

The processes and workflows for quality control have been described in detail, so why quality control is performed needs explanation. Undoubtedly, the major reason is to ensure access to our abundant collection of print and electronic resources. Library resources would be in circulation much faster without quality control, but there is greater potential for a variety of mistakes to render the library’s catalog useless.

Over the years, a host of issues have been uncovered due to the lack of quality control in the early years of the Marx Library. Books with misspelled words or incorrect subfield indicators in the MARC title field for titles that begin with an article, “A,” “An,' or “The,” have disappeared from the OPAC and discovery service side of searches. The wrong LC number has sent users on the hunt for a book never to be found or shelved in a very different subject area. A barcode was applied to only the first volume of a multivolume set and there was no barcoded record of the existing volumes. Name and subject authority control, was inconsistent so multiple instances of names or subjects were displayed during a search. Different formats of titles shared the same bibliographic identity which confused users on what format they were looking for. A prime example of this issue was a DVD version of a title was placed on the same holding as the VHS tape version.

Outsourcing some of our physical processing has greatly expedited the wait time for new books to enter circulation. However, this does not mean these books are $100 \%$ mistake free. It is still necessary for catalogers to check the prescribed LC call number as well as to make sure the book is not part of a series that adheres to a different local LC structure or a juvenile title that does not follow our local LC practice. Propas \& Johnson (1998) make the case for librarians to 
implement their own checks to make sure the quality of vendor services is acceptable and for professional librarians to "continue to maintain the intellectual understanding of what constitutes bibliographic integrity and quality."

Because we have instituted a detailed quality control process and greatly improved staff training, these mistakes no longer happen or the issue is caught and corrected before library users have access to the resource. As cataloging personnel dwindles and technical services staff are asked or required to leave their comfort areas to work in public services, there is the temptation to let some things go. However, the inspection of the bibliographic and physical quality of the resources should not be one of those processes that falls by the wayside; it's too important. Without the bibliographic inspection of records, easily corrected errors or misunderstanding of rules go unrevealed and cataloging staff continue to commit erroneous mistakes. Bade (2008) contends that library users are not looking for a perfect record but simply want to find what they are looking for. However, in order for library users to find the best information for their research, the cataloging records should be in high quality and mistake free, and the format of the resources should be clearly discernible to the user.

In summation, Hanson \& Schalow (1999) give the most convincing statement on why the Marx Library Cataloging department performs quality control: "Delivering quality in technical services requires that we strive to meet what often seem to be competing expectations from our customers: rapid availability of library materials as well as detailed and accurate cataloging and processing of those materials." Ultimately, it is the responsibility of the cataloging team to perform quality control to identify problems, implement solutions, and take ownership of the bibliographic integrity of the collection.

\section{CONCLUSION}

At this juncture, the Marx Library Cataloging Department will continue to follow its current workflow and procedures for quality control. Despite a smaller book budget and a small cataloging staff compared to other academic institutions, the Cataloging Department is, nevertheless, able to provide an effective level of quality control for cataloged materials. However, several factors could initiate changes to the current process, such as a dramatic increase in the book budget and the attrition of cataloging librarians and staff due to retirement or other reasons without rehiring for these positions. The department's motto is that the quality of work is more important than the quantity of work produced. Our motto is similar to Khurshid's (1997) Total Quality Management (TQM) philosophy on doing it right the first time. It is fruitless to rush the cataloging process only to boost monthly output statistics if the work is riddled with mistakes. If more emphasis is placed on training and the reasons why things are done in a certain way, output will increase naturally and without mistakes. This encourages the cataloging librarians and staff to take pride in their work and to seek opportunities to increase their cataloging knowledge and skills. Paiste (2003) refers to this as building a "culture of quality" which embodies the following aspects: holding a systems (departments, libraries, institutions) view, pride in workmanship, valuing and empowering employees, and personal learning. 
Additionally, inspecting the physical processing of materials is as important as inspecting the data in the bibliographic, holdings, and item records. An error free record is the ultimate goal; however, if the call number or barcode do not match the right item, this item is rendered inaccessible. The quality control of cataloged materials is a comprehensive process that follows a set of workflow to ensure the accuracy of the bibliographic, holdings, and item records. The physical processing must coincide with the information in these records so the library's collection is accessible to students, faculty, and researchers.

In conclusion, the loss of quality control would be harmful to the integrity and accessibility of the library's resources. "The battle to maintain quality must go on, error must be kept to a minimum” (Soules, 1983). As Sheeran (1996) said, "the bibliographic database is at the center of the library, and, in order to provide effective access to the library materials, it must necessarily be a high quality.” The Marx Library Cataloging Department will continue to provide some level of quality control to maintain a cohesive collection and to adhere to the library's mission statement to provide timely and efficient access to resources.

\section{References}

Bade, D. (2008). The perfect bibliographic record: Platonic ideal, rhetorical strategy or nonsense?. Cataloging \& Classification Quarterly, 46(1), 109-133. https://doi.org/10.1080/01639370802183081

Chen, S. (2008). Empowering student assistants in the cataloging department through innovative training: The E-Learning Courseware for Basic Cataloging (ECBC) Project. Cataloging \& Classification Quarterly, 46(2), 221-234. https://doi.org/10.1080/01639370802177646

Graham, P. S. (1990). Quality in cataloging: Making distinctions. The Journal of Academic Librarianship, 16(4), 213-218. Retrieved from Professional Development Collection.

Hanson, H., \& Schalow, J. (1999). Two aspects of quality in technical services: Automating for quick availability, and identifying problems, effecting solutions. Library Collections, Acquisitions, \& Technical Services, 23(4), 433-441. https://doi.org/10.1080/14649055.1999.10765621

Harmon, J. C. (1996). The death of quality cataloging: Does it make a difference for library users? The Journal of Academic Librarianship, 22(4), 306-307. https://doi.org/10.1016/s0099-1333(96)90124-X

Hider, P., \& Tan, K. C. (2008). Constructing record quality measures based on catalog use. Cataloging \& Classification Quarterly, 46(4), 338-361. https://doi.org/10.1080/01639370802322515

Khurshid, Z. (1997). The application of TQM in cataloguing. Library Management, 18(6), 274279. https://doi.org/10.1108/01435129710176706

McGurr, M. (2008). Improving the flow of materials in a cataloging department. Library Resources \& Technical Services, 52(2), 54-60. http://dx.doi.org/10.5860/lrts.52n2.54

Paiste, M. S. (2003). Defining and achieving quality in cataloging in academic libraries: A literature review. Library Collections, Acquisitions, and Technical Services, 27(3), 327338. https://doi.org/10.1016/s1464-9055(03)00069-1

Park, J., Tosaka, Y., Maszaros, S., \& Lu, C. (2010). From metadata creation to metadata quality control: Continuing education needs among cataloging and Metadata 
professionals. Journal of Education for Library and Information Science, 51(3), 158-176. Retrieved from JSTOR.

Petrucciani, A. (2015). Quality of library catalogs and value of (good) catalogs. Cataloging \& Classification Quarterly, 53(3-4), 303-313. https://doi.org/10.1080/01639374.2014.1003669

Propas, S. W., \& Johnson, S. (1998). Outsourcing, quality control, and the acquisitions professional. Library Acquisitions: Practice \& Theory, 22(3), 279-285. https://doi.org/10.1016/S0364-6408(98)00082-9

Schultz-Jones, B., Snow, K., Miksa, S., \& Hasenyager Jr, R. L. (2012). Historical and current implications of cataloguing quality for next-generation catalogues. Library Trends, 61(1), 49-82. Retrieved from Project Muse.

Sheeran, R. (1996). Maintaining the cohesive collection: The case for the local cataloger. The Journal of Academic Librarianship, 22(6), 462-465. https://doi.org/10.1016/s00991333(96)90009-9

Soules, A. (1983). The deterioration of quality cataloging. Library Journal, 108(1), 27-29. Retrieved from Academic Search Complete.

University of Illinois at Urbana-Champaign (n.d.). MarcEdit: An introduction to the MARC record editing software MarcEdit. Retrieved from http://guides.library.illinois.edu/c.php?g=463460\&p=3168262

University of South Alabama (n.d.). University of South Alabama libraries mission statement. Retrieved from http://www.southalabama.edu/departments/library/resources/missionstate.pdf

\begin{abstract}
About the authors
Muriel D. Nero, Senior Librarian, is the Head of Cataloging at the Marx Library of the University of South Alabama. She received her Master of Library and Information Science from the University of Alabama. Her research interests include the future of cataloging for academic libraries and professional development for library staff.

Jia He, Assistant Librarian, is the Cataloging Electronic Resources Librarian at the Marx Library of the University of South Alabama. She received her Master of Library and Information Science from the University of Wisconsin Milwaukee. Her research interests include technical services in academic libraries and library services for international students.
\end{abstract}

